\title{
Extraction and processing of Bast fibres from Ficus glomerata- A new source for non- conventional fibres
}

\section{Aaditaa*}

Department of Clothing and Textiles, College of Home Science, G.B. Pant University of Agriculture and Technology, Pantnagar (Uttarakhand), India

Shahnaz Jahan

Department of Clothing and Textiles, College of Home Science, G.B. Pant University of Agriculture and Technology, Pantnagar (Uttarakhand), India

*Corresponding author. E-mail: aaditaasingh@gmail.com

\begin{abstract}
The increasing global preference towards the natural products rather than synthetic products has increased the attraction of tourists to the local markets. Ficus glomerata fibres is one of the suitable source as raw material for making natural products like carrier bags, baskets, belts and some handicraft items. Fibres from F. glomerata stems were extracted by using water retting method. After retting, the fibres were scoured using sodium hydroxide $(\mathrm{NaOH})$ for making them suitable to form the different produucts from the processed fibres such as yarn, nonwoven, woven and knitted fabrics. Scouring conditions such as chemical concentration and processing time were evaluated on the basis of physical properties of fibres such as tenacity, elongation and fineness. The optimization results obtained from testing of physical properties of fibres shows that, the $3 \%$ concentration of sodium hydroxide $(\mathrm{NaOH})$ and 60 minutes processing time was found promising for the treatment of fibres. The improvement in $F$. glomerata fibres through proper processing can yield value added fibres and thus can enhance the potential utility of these fibres in diversified sectors. So, the $F$. glomaerata fibres has a potential to provide an important role in making space for natural fibre products in the outside market.
\end{abstract}

Keywords: Elongation, Ficus glomerata, Fineness, Scouring, Tenacity, Water retting

\section{Article Info}

DOI: 10.31018/jans.v10i2.1759 Received: February 19, 2018

Revised: March 18, 2018

Accepted: April 25, 2018

How to Cite

Aaditaa, and Jahan, $\mathrm{S}$ (2018). Extraction and processing of Bast fibres from Ficus glomerata- A new source for non- conventional fibres. Journal of Applied and Natural Science, 10(2): 661 - 666

\section{INTRODUCTION}

India has wide range of flora and fauna and popular for its dense forest cover ranging from Himalayan temperate to dry zone forest. Among the plant species, commonly used by man, the fibre yielding plants holds the second position after food plants in their economic importance (Pandey and Gupta, 2003). Fibre based plant resources have played a key role in immemorial and are still deeply associated and serving a large number of human population throughout the world (Negi et al, 2010).

International Jute Study Group (2012) has given the requirement of different sectors such as food grade jute bags, packaging materials, geo textiles and automobile industries which have a very high demand of natural fibers and these industries directly or indirectly provides employment and work to more than 12 millions of farmers, 1 million of industrial workers and 0.60 million of artisans workers which are working in more than 18 countries from Asia and Africa.

Uttarakhand state is blessed with a rich variety of fibre yielding plants but they are restricted to an area and have not received any commercial im- portance. Among various fibre giving plants such as Grewia optiva (bhimal), Stinging Nettle (bichhu ghas), Hibiscus cannabinus (kenaf) etc, and another potential source is Ficus. glomerata which is locally known as 'gular'. The famous medicinal plant of India belongs to Moraceae family. It is also known as 'cluster fig tree' and since longer period of time it has been used in traditional system of medicine.

$F$. glomerata plant is cultivated and grown not only in hills of Uttarakhand, but also in Punjab, Nagpur, Kolkatta, Bihar, Orrisa, Rajasthan and some, parts of South India. The height of 'gular' plant is about $10-16$ metres and the bark is about 0.5 to $1.8 \mathrm{~cm}$ thick. F. glomerata plant has medicinal value and most of the parts of plants are utilized for curing various health problems. The bark of tree is useful for urological disorders, diabetes etc. Other parts of plants such as leaves, fruits and roots are used for treatment of various disorders and they also have wound healing, analgesics, anti-fungal and anti-inflammatory properties (Parakh, 2009). In this study, the stems of $F$. glomerata plant were utilized for the extraction of fibres. The extracted fibres were processed using sodium hydroxide 
and its variables were optimized by testing the physical properties such as tenacity, fineness, elongation of fibre.

\section{MATERIALS AND METHODS}

Procurement of raw materials: The raw materials were obtained from Garden Section, G.B. Pant University of Agriculture and Technology located in Pantnagar, Uttarkhand. The stems of F. glomerata were harvested in month of October 2014. The plant stems were bundled which weighs about $7 \mathrm{~kg}$.

Retting of $\boldsymbol{F}$. glomerata stems: The collected stems of $F$. glomerata were cut into 6 inches length with the help of sickle. The leaves and pods from stems were rippled and tied in 2 bundles. F. glomerata fibres were extracted from stem by using water retting extraction process. In water retting process, the bundles of stems were submerged in tank filled with water. During retting, an extra weight is put over bundles to keep them in place, because the formation of gas causes the bundle to rise on the water surface (Tahir et al ,2011).

Retting is a biochemical decomposition process which is carried out in stagnant water and in the presence of microbes. Ahmed and Akhter (2001) described that the process of retting is best carried out in the water which contains good amount of salts, minerals, iron and calcium content. The optimum $\mathrm{pH}$ and temperature for water retting is 7 and $35^{\circ} \mathrm{C}$ respectively. For the best results $15 \mathrm{~cm}$ of the water should left over the jute bundle. The diameter of the jute bundle should be $20 \mathrm{~cm}$ and has a plant water ratio nearly 1:20.

This retting process provides an environment that enhances the growth of microbes both in water and stems. The microbe separates the fibres from stems by degrading the pectinious substances, gum and other mucilaginous matter that binds the fibres with plant tissues.

Faulk et al.(2008) mentioned that retting is mainly carried out by anaerobic bacteria such as Clostridium spp., which lives in rivers, lakes, ponds and produces pectinases and other enzymes which are responsible for retting the fiber.

After the completion of water retting, the stems were washed to remove gummy layer present over them. The amount of water which was required to wash the gummy layer from the stem was approximately 10 litres $/ \mathrm{Kg}$ of biomass. Then, stems were dried in shade to remove excess of water. With the help of long wooden hammer, the stems were beaten to separate fibres from stems. The separated fibres were then kept for drying in open air. The obtained moisture content in the isolated fibre of $F$. glomerata was about $6.83 \%$.

Optimization of scouring variables for $F$. glomerata fibres: The retted fibres were subsequently cleaned; the fibres were pre-treated to remove impurities and non-structural components (ash, fats and waxes). The natural impurities present in fibres possesses lignin (17\%), hemicellulose $(22.41 \%)$, ash $(0.7 \%)$, fats and waxes $(1.5 \%)$. These impurities causes the fibre bundles to glued together and provide excellent strength but less pliability.

Due to presence of impurities, fibres are coarse and having muddy white appearance. The coarseness in fibres causes difficulties in spinning of yarn and fabric construction. Hence, there is need of scouring process to remove impurities from fibres and separate them to make it suitable for textile purpose.

The commercial process of scouring involves the treatment of retted fibres with sodium hydroxide $(\mathrm{NaOH})$ solution at optimum temperature and time varying with type of fibre. For example in case of chemical processing of semal bast fibres (Pathak, 2014), the optimum concentration of sodium hydroxide $(\mathrm{NaOH})$ was found to be $3 \%$ and the processing time effective for scouring was found to be 60 minutes.

The alkali treatment using sodium hydroxide $(\mathrm{NaOH})$ is a versatile one as it provides minimum strength and weight loss, safe from degradation point of view and it brings about change in the morphology, crystalline structure and chemical composition of the fibres which induce absorbency property in fibres like coir, flax, sisal fibres (Vardhini et al, 2016).

This study shows the optimization of variables for scouring of $F$. glomerata fibres. Variables which were optimized during the processing of F. glomerata fibres were the processing time and concentration of sodium hydroxide.

During the chemical processing a balance between the different variables of processing should be maintained so that it will give an effective chemical treatment to the fibre. If the variables of chemical processing is not balanced it may cause a damaging effect. So, there should be a balance between the above mentioned variables i.e. processing time and concentration of sodium hydroxide. So, the optimization of variables is important to maintain the quality of fibres in terms of the physical properties.

Optimization of concentration of sodium hydroxide: The variable i.e. concentration of sodium hydroxide $(\mathrm{NaOH})$ was optimized at 5 different concentrations. F. glomerata fibres were treated with $1 \%, 2 \%, 3 \%, 4 \%$ and $5 \%$ of $\mathrm{NaOH}$ at $100^{\circ} \mathrm{C}$ for 1 hour. The material liquor ratio of $1: 50$ was kept constant throughout the experiment. A solution of volume $500 \mathrm{ml}$ was made and separately put in five different beakers containing $10 \mathrm{~g}$ of fibre sample.

After alkali processing it is necessary to neutralize the alkali by treating the sample with acetic acid $\left(\mathrm{CH}_{3} \mathrm{COOH}\right)$, hydrochloric acid $(\mathrm{HCl})$ or 
dil.sulphuric acid $\mathrm{H}_{2} \mathrm{SO}_{4}$. So after treatment with $\mathrm{NaOH}$, fibres were neutralized with $0.2 \%$ concentration of $\mathrm{CH}_{3} \mathrm{COOH}$ solution for 10 minutes followed by usual washing and drying in air.

The optimum concentration was finalized in terms of the physical properties of fibre. The properties such as tenacity (g/denier), elongation(\%) and fineness(denier) were determined at each concentration of sodium hydroxide $(\mathrm{NaOH})$. The concentration which gave higher value of physical properties was considered as an optimum concentration of sodium hydroxide for scouring of $F$. glomerata fibres.

Optimization of scouring time: To optimize the scouring time, the fibres weighing about $10 \mathrm{~g}$ were scoured at three different durations. Three durations which were taken are 30,60 and 90 minutes because below 30 minutes the scouring is not effective for removing impurities. This is justified with the study of Hashim et al. (2016) who also carried out scouring using $2 \%(\mathrm{NaOH})$ solution kenaf bast fibres at $27^{\circ} \mathrm{C}$ for 30 minutes. Based on the optimized concentration of sodium hydroxide $(\mathrm{NaOH})$, three different solutions were prepared. The material liquor ratio of 1:50 was taken and processing is carried out at a temperature of $100^{\circ} \mathrm{C}$. After scouring, the samples were washed and neutralized with method as mentioned above. The optimum duration was finalized on the basis of values of physical properties of fibres tested for each sample scoured with different time period. The sample which shows higher value of tenacity, elongation and fineness were selected as an optimum duration for scouring of $F$. glomerata fibres.

Testing of physical properties of fibres: The testing of physical properties of fibre was conducted at Pasupati Acrylon Ltd., Thakurdwara, Uttar Pradesh. The tests for physical properties such as tenacity, elongation and fineness were determined by using tensile testing machine. The testing apparatus which was used are Fafegraph-M for testing single fibre strength and Vibromat-M for determining fineness.

Both apparatus work in joint operation as a semiautomatic microprocessor. The apparatus has controlled tensile strength tester which is based on principle of Constant Rate of Extension (CRE). Firstly, the fineness of fibre was tested by using Vibromat -M. In Vibromat-M, the fiber was hanged at the place provided with suitable pretension clips, one end of fibre was held in a clamp and other end was loaded with weight. The reading of fibre fineness was noted from digital scale of Vibromat-M. The test was repeated ten times and average was calculated.

After this, the same fibre was transferred to Fafegraph-M for testing tenacity and elongation. With the help of forceps, the fibre sample was clamped between the two jaws of Fafegraph-M. The jaws were separated at the gauge length of
$20 \mathrm{~mm}$. Due to the downward movement of jaw a tensile force is exerted on the fibres which will leads to the breakdown of fibre.

Both the jaws opened immediately and lower jaw moved upward to the specific gauge length. After every test the values of DTE (Denier, Tenacity and Elongation) were noted. Ten readings were taken for each sample to calculate average tenacity and elongation.

\section{RESULTS AND DISCUSSION}

The physical properties of fibre scoured using different concentration of $\mathrm{NaOH}$ and processing time were tested and results are given in Table 1 and 2 . Optimized concentration of sodium hydroxide for scouring: Table 1 depicts the properties of $F$. glomerata fibres scoured with different concentration of sodium hydroxide i.e. $1 \%, 2 \%, 3 \%, 4 \%$ and $5 \%$ to find out most suitable concentration of sodium hydroxide for scouring.

It is evident from Table 1 that at $1 \%$ concentration of $\mathrm{NaOH}$, fibres has maximum tenacity of $4.105 \mathrm{~g} /$ denier. But the elongation and fineness at $1 \%$ concentration has been reported minimum. The most probable reason behind the above finding is that fewer impurities might have been removed from fibre surface and there is less separation of individual fibres.

The above explanation is supported with the findings of Zannen et al. (2014) who have stated that the fibres treated with lower concentration of sodium hydroxide have high tenacity but the removal of impurities from fibres was less. The fibres obtained at a lower concentration of alkali treatment have average quality. When increasing treatment concentrations, the physical properties such as fineness and elongation of fibres were improved and it results in removal of more impurities from fibres.

Samanta et al. (2007) found that there is an increase in crystallinity in case of treatment with $(\mathrm{NaOH})$.This is due to some loss of impurities such as hemicellulose and other minor constituents from the non-crystalline part because of the swelling action of $(\mathrm{NaOH})$ treatment. There is an effect on structural reorientation and stress re-distribution of the molecular chain.

As the concentration of sodium hydroxide increases, there was an increase in the value of elongation and fineness of fibres. At 4 and $5 \%$ concentration of $\mathrm{NaOH}$, the fibres have maximum elongation and fineness but decrease in fibre strength was observed with increasing concentration.

In accordance with above justification, Nalankalli et al. (2008) stated that when the fibres were treated with alkali, the impurities that are present in molecular chains in primary and secondary walls are removed. This causes the reduction of fibre strength at higher concentration as the fibre structure become open. 
Table 1. Properties of $F$. glomerata fibres scoured with different concentration of sodium hydroxide.

\begin{tabular}{lllllllll}
\hline S.N. & Fibre Property & \multicolumn{7}{l}{ Sodium hydroxide Concentration } \\
\cline { 3 - 8 } & & $\mathbf{1 \%}$ & $\mathbf{2 \%}$ & $\mathbf{\# 3 \%}$ & $\mathbf{4 \%}$ & $\mathbf{5 \%}$ & $\mathbf{C D}$ & F-value \\
\hline 1. & Tenacity (g/denier) & 4.105 & 3.57 & 3.48 & 2.48 & 2.21 & 0.647 & $26.21^{* *}$ \\
2. & Elongation (\%) & 1.21 & 1.37 & 2.20 & 3.16 & 3.77 & 0.210 & $482.40^{* *}$ \\
3. & Fineness (denier) & 22.35 & 20.44 & 18.70 & 17.85 & 17.32 & 3.76 & $5.19^{* *}$ \\
\hline
\end{tabular}

\# selected duration ** Significant difference at $1 \%$ level of significance CD-Critical Difference

Table 2. Properties of $F$. glomerata fibres scoured for different duration.

\begin{tabular}{lllllll}
\hline S. N. & Fibre property & \multicolumn{7}{c}{ Scouring time (minutes) } \\
\hline & & $\mathbf{3 0}$ & $\mathbf{\# 6 0}$ & $\mathbf{9 0}$ & CD & F-value \\
\hline 1. & Tenacity (g/denier) & 3.78 & 3.59 & 2.49 & 13.35 & $60.761^{* *}$ \\
2. & Elongation (\%) & 1.425 & 2.41 & 1.84 & 0.29 & $57.22^{* *}$ \\
3. & Fineness (denier) & 22.25 & 22.14 & 20.44 & 2.52 & 4.131 \\
\hline
\end{tabular}

\# selected duration * Significant difference at $1 \%$ level of significance CD-Critical Difference

Findings of Kyung and Obendrof (2006) are also in agreement with the above explanation. They reported that the strength is imparted to bast fibres by a non-fibrous material i.e. lignin which forms hydrogen bonds with cellulose of fibres. Due to alkali treatment lignin is removed which leads to decrease in strength of bast fibres.

According to Sen et al. (1987), fibres undergo partial conversion to cellulose II on treatment with $\mathrm{NaOH}$. The conversion increases with the increase in concentration of sodium hydroxide $(\mathrm{NaOH})$.

The reason for this conversion is reported by Benyahia et al. (2013) in his study on effect of alkali treatment on alfa fibre properties. They stated that cellulose on reaction with alkali reduces the hydrogen bonding of cellulose hydroxyl groups by the removal of the carboxyl group. Therefore, the numbers of hydroxyl groups $(\mathrm{OH})$ were decreased. In addition, a part of lignin was removed from the fiber. It effects the physical properties of fibres on treatment with $\mathrm{NaOH}$ solution.

It is clear from the Table 1 that fibre sample scoured with 1 and 2 per cent sodium hydroxide $(\mathrm{NaOH})$ concentration had maximum tenacity but the other properties such as elongation and fineness were not good. Hence, the fibres treated with lower concentration makes the fibre stiff with less pliability because of less separation of fibres. Therefore, 1 and 2 per cent sodium hydroxide $(\mathrm{NaOH})$ concentration was not considered optimum for scouring F. glomerata fibres.

By analyzing the above table, it was observed that the use of more than 3 per cent sodium hydroxide $(\mathrm{NaOH})$ for scouring of fibres shows a drastic decrease in tenacity of fibres. This is due to the reason reported by Wang and Cai (2009) in their study that breaking strength of jute fibres decreases and fineness of fibres increases as concentration of sodium hydroxide $(\mathrm{NaOH})$ was increased during processing of fibres.

Therefore 3 percent concentration of sodium hydroxide $(\mathrm{NaOH})$ was considered optimum for scouring of $F$. glomerata fibres. It is clear that at 3 percent concentration there is complete removal of impurities from fibre surface and displays the higher elongation and tenacity then fibres scoured at 4 and 5 percent. The fibres which are processed at $3 \%$ concentration shows fineness of about 18.70 denier, which indicates suitable softness and pliability of fibres.

In order to conclude the above results, a statistical analysis was made which shows the effect of different concentration of sodium hydroxide $(\mathrm{NaOH})$ on the various physical properties of fibre. F- Values were calculated from one way analysis of variance as shown in Table 1. F-values shows that there is a significant difference in tenacity, elongation and fineness of fibres at $1 \%$ level of significance.

Optimized scouring time: In accordance with the optimized concentration of sodium hydroxide $(\mathrm{NaOH})$ for scouring, the $F$. glomerata fibres were scoured using $3 \%$ concentration of sodium hydroxide $(\mathrm{NaOH})$. The effect of treatment time on the properties of fibre was conducted at three different durations i.e. 30, 60 and 90 minutes.

The result displayed in Table 2 shows the physical properties of fibres such as tenacity, elongation and fineness for three different time durations.

As shown in Table 2, it is clear that tenacity of fibre decreases with the increasing scouring time. Fibres scoured for 30 minutes have maximum tenacity of $3.78 \mathrm{~g} /$ denier followed by 60 minutes (3.59g/denier) and 90 minutes $(2.49 \mathrm{~g} /$ denier $)$. The most probable reason for this is that due to the shorter scouring time alkali was not able to react with the $\mathrm{OH}$ and $\mathrm{COOH}$ group of cellulose. Hence partial removal of gum, lignin and other impurities from fiber surface make them brittle and restricts their application in textiles.

Above statement can be justified from the study of Mahjoub et al. (2014). They evaluated the effect of different time duration of alkali processing on the tensile properties of kenaf fibres. They found that the kenaf fibres shows decreased tensile properties by increasing the treatment time. They also stated that in comparison with untreated kenaf fibres, the alkali treated fibres have lower tensile properties. 
Conversely, findings of Hashim et al. (2014) are also in accordance with above justification. They stated that when the alkali treatment conditions such as concentration, duration and temperature was set higher, the kenaf fibres shows lower tensile properties.

In order to obtain soft and pliable fibres, it is necessary to remove lignin and other non-cellulosic components from fibres. However, removal of lignin has direct effect on the elongation of fibres, as the amount of lignin decomposition increases the elongation of fibre also increases.

The result shows that, the elongation values obtained after 30 minutes of scouring time are found to be less as compared to 60 and 90 minutes. Therefore, scouring time of 30 minutes may not be the sufficient time for removal of lignin. The reason behind this is that, to decompose lignin proper time is required by fibre to swell, so that chemical can exhaust inside the fibres.

The above reason is in accordance with the findings of Vardhini et al. (2016); they reported that proper treatment time can influence lignin decomposition. Even higher concentrations of $\mathrm{NaOH}$ at lower treatment time do not have much impact on the removal of lignin.

However, decrease in values of elongation is observed in case of treatment time of 90 minutes. The value of elongation at 90 minutes scouring time was found to be 1.84 percent as compared to 60 minutes i.e. 2.41 percent respectively. The reason behind this is that prolonged treatment time results in deterioration of cellulosic materials of fibre. The alkali deeply penetrates into the crystalline region of cellulose due to exceeded heating time which results in breaking up of bonds between lignin and cellulose. This causes a damaging effect to the fibre properties and makes it inefficient for various applications.

Oudiani et al. (2012) in their study of Agave fibres, analyzed that at lower treatment time the penetration of alkali solution is in amorphous region. But as the treatment time increases the fibre swells and alkali solution penetrate into the crystalline region of cellulose fibres. The penetration of caustic soda in crystalline region weakens the inter chain forces and ruptures bonds and cellulose molecules arranged in fibres. As stated by Goswami et al. (1995), the reason of high tensile properties of fibres is mainly due to its highly oriented and crystalline structures of molecules arranged uniformly inside the fibre.

The fineness of fibres is another important property which affects the behavior of fibres during production of yarn and fabric. The increased fineness also contributes to the softness and pliability of fibres.

Table 2 reveals that, F. glomerata fibre sample scoured for 90 minutes have maximum fineness i.e. 20.44 denier, as compared to other two sam- ples. This is because of the same reason that with increase in scouring time more impurities and cellulosic components might have removed from fibre, and resulted in finer fibres.

Therefore, it can be concluded from the above results that fibres scoured for 30 minutes have maximum tenacity, but lower values of elongation and fineness are observed. Removal of lignin is found poor and presence of which makes the fibre coarse and brittle. Presence of lignin also restricts application of fibres in textiles and other industrial sectors. Hence, 30 minutes time for scouring of $F$. glomerata fibres is not suitable.

Lower values of tenacity and elongation of fibres are observed in case of 90 minutes time duration with highest value of fineness. Though the fibres are fine but due to removal of cellulosic materials, fibres become weak and hence not suitable for further use.

Among all, lowest reduction in strength is observed in case of 60 minutes scouring time. The sample exhibits highest elongation and moderate fineness and efficiently retains properties to an appreciable extent. In addition, the fibres are soft and pliable because of proper separation of fibres. The treatment of fibres at 60 minutes time duration not only improves the properties but also minimizes the impurities present on the surface of fibre. The duration of 60 minutes also contributes to the prevention of alkali penetration in crystalline region of fibre which otherwise may cause excessive cellulose degradation resulting in reduction of tensile properties.

Hence duration of scouring treatment is suitable for scouring large batch of fibres. Therefore, 60 minutes time was considered optimum for scouring of $F$. glomerata fibres.

One way ANOVA test was carried out to analyze the significance of physical properties on different scouring durations. The F-values found significantly different between tenacity and elongation at $1 \%$ level of significance. No significant difference was found between fineness of fibres treated for different scouring time.

\section{Conclusion}

This study explores and gives new ideas related to the F. glomerata plant species which can be a future bast fibre though, the other parts of the plants have been utilized for enumerable medicinal treatments such as diarrhoea, dysentery, diabetes, respiratory and urinary diseases because of its curative and therapeutic properties. Besides the medicinal use of the $F$. glomerata plant, its stems can be utilized to extract fibre for the development of sustainable products. So, this is a newer approach to the textile manufacturers which they can incorporate in their industries to prepare natural and ecofriendly fibres from $F$. glomerata plant species. This fibre is in its initial phase so it 
can be a viable option for small scale industries. The availability of these pant species throughout the India is very high so it would be a potential source for the small scale industries to prepare different products from this fibre like yarns, fabric, nonwovens or composite structures. F. glomerata fibres because of its biodegradability, can also be used in making ropes, twines, paper, boards and wide variety of agrotextile products. Among its wide variety of uses, bast fibre has a very high potential and a bright future.

\section{REFERENCES}

Ahmed, Z. and Akhter, F. 2001. Jute Retting: An overview. Online Journal of Biological Sciences. 1(7): 685 -688 .

Benyahia, A., Merrouche, M., Rokbi, M. and Kouadri, Z. (2013). Study the effect of alkali treatment of natural fibers on the mechanical behavior of the composite unsaturated Polyester-fiber Alfa. French Mechanical Congress.

Faulk, J.,Danny, E. and Dodd, B. 2008. Influence of pectinolytic enzymes on retting effectiveness and resultant fibre properties. Bioresources. 3(1): 155169.

Goswami, K. K., Das N.N. and Mukherjee, A.K. (1995). SEM and IR studies on scouring and bleaching of Linen. Indian Journal of Fiber and Textile Research. 20: 28-33.

Hashim, Y.M., Roslan, N.M., Omar, M., Omar, F.M., Mahzan, Z. M., Shahruddin and Saparuddin , A. (2014). The impact of alkali treatment conditions on tensile strength of Kenaf fiber. Applied Mechanics and Materials. 660: 285-289.

Hashim, Y., Roslan, N., Marwah, O., Mahzan, S., Zin, M. and Ariffin, S. 2016. The effect of alkali treatment conditions on tensile strength of kenaf fiber. Asian Research Publishing Network Journal of Engineering and Applied Sciences. 11(14):8658-8662.

International Jute Study Group.2012. Report on world jute and kenaf statistics:at a glance (Jute, Kenaf other bast and hard fibres : farm and fashion). Dhaka, Bangladesh.13p. Retreived on 13/7/2015from http:// jute. $20 \% 20 \%$ kenaf $\% 20$ stat $\% 20$ at $\%$ 20glance ijsg.pdf.

Kyung, H.S and Obendorf, K. S. (2006). Chemical and biological retting of Kenaf fibres. Textile Research Journal. 76(10):751-756.

Mahjoub, R., Jamaludin, Y.M., Sam, M.R.A. and Hashemi, S.H. (2014). Tensile properties of kenaf fiber due to various conditions of chemical fiber surface modifi- cations. Construction and Building Materials. 55:103113.

Nalankalli, G., Saravanan , D., Govindaraj, N. and Harish, P. (2008). Efficacy of solvent, alkali and pectinase on removal of non cellulosics from cotton fibres. Indian Journal of Fiber and Textile Research. 33(4): 438-442.

Negi, S.V., Maikhuri, K.R., Rawat, S.L. and Phondani, C. P. (2010). Current status and future potential of fiber yielding crop Hibiscus cannabinus $L$. in mountain region of Central Himalaya. International Journal of Science and Technology. 5: 87-96.

Oudiani, E.A., Chaabouni, Y., Msahli, S. and Sakli, F. (2012). Mercerization of Agave americana L. fibers. The Journal of Textile Institute. 103(5):565-574.

Pandey, A. and Gupta, R. (2003). Fibre yielding plants of India: Genetic Resources, perspective for collection and utilisation. Natural Product Radiance. 2 (4):194-204.

Parakh, P. 2009. F. racemosa Linn.- Overview. Natural Product Radiance. 8(1):84-90.

Pathak, S. 2014. Extraction, processing and evaluation of physico-chemical properties of semal (Bombax ceiba) fiber and construction of woven and nonwoven structures. Thesis, Ph.D, G.B.Pant University of Agriculture and Technology, Pantngar, 102-106p.

Samanta, A.K., Singhee, D., Basu, G. and Biswas, S.K. 2007. Thermal behaviour and structural features of chemically and biochemically modified jute substrate. Indian Journal of Fibre and Textile Research. 32(2): 355-365.

Sen, K. K., Saha, C .S and Ray, K.P. (1987). Physical and structural properties of raw and alkali treated bhindi (Hibiscus esculentus L) Fibre. Indian Journal of Fiber and Textile Research. 12:152-153.

Tahir, T., Ahmed, A., Syeed, O.A., Azry,S. and Ahmed, Z. (2011). Retting process of some bast plant fibres and its effect on fibre qulity: A review. BioResources. 6(4): 5260-5281.

Vardhini, R., Vishnu, J.K., Murugan, C., Tamil, S. and Surjit, R. (2016). Optimization of alkali treatment of banana fibres on lignin removal. Indian Journal of Fibre and Textile Research, 41(1):156-160.

Wang,W.M., Cai, Z.S. and Xia, W.P.(2009). Changes in composition, structure and properties of jute fibres after chemical treatments. Fibres and Polymers.10 (6): $776-780$

Zannen, S., Ghali, L., Halimi, M.T and Hssen, M.B. (2014). Effect of chemical extraction on physicochemical and mechanical properties of Doum Palm fibres. Advances in Materials Physics and Chemistry. 4(10): 203-216. 